\title{
KOMPOSISI GULMA PADA BERBAGAI JARAK TANAM PADI SECARA IPAT-BO DAN KONVENSIONAL
}

\section{WEED COMPOSITION ON DIFFERENCE PLANT SPACING LOWLAND RICE IN SOBARI AND CONVENTIONAL METHODS}

\author{
Merry Antralina $^{1)}$, Yuyun Yuwariah ${ }^{2)}$, dan Tualar Simarmata ${ }^{2)}$ \\ ${ }^{1)}$ Fakultas Pertanian Universitas Bale Bandung, Jalan RAA Wiranatakusumah \\ No. 7 Baleendah Bandung. Telp (022) 5897702 \\ ${ }^{2)}$ Fakultas Pertanian Universitas Padjadjaran, 45363 Jatinangor, Sumedang \\ Korespondensi : mantralina@yahoo.com
}

Diterima 6 Oktober 2014/ Disetujui 12 Desember 2014

\begin{abstract}
ABSTRAK
Penelitian yang bertujuan mempelajari komposisi gulma tanaman padi sawah pada sistem bertanam secara IPAT-BO dan konvensional telah dilaksanakan pada bulan April 2013 sampai bulan Juli 2013 di Kelompok Tani Sadang Mukti, Kampung Sadang Sari, Kabupaten Bandung Jawa Barat yang terletak pada ketinggian $668 \mathrm{~m}$ di atas permukaan laut. Penelitian menggunakan metode eksperimen, dengan Rancangan Petak Terpisah, 3 kali ulangan, sebagai petak utama yaitu faktor metode pengairan (M), yang terdiri dari pengairan secara IPAT-BO dan konvensional, sedangkan anak petak adalah jarak tanam (J), yang terdiri dari : $30 \times 35 \mathrm{~cm}$, $30 \times 25 \mathrm{~cm}, 35 \times 35 \mathrm{~cm}$, dan $30 \times 30 \mathrm{~cm}$. Hasil penelitian menunjukkan bahwa terjadi interaksi antara metode pengairan dan jarak tanam terhadap nilai jumlah dominasi gulma, dan bobot kering gulma.Gulma yang dominan pada perlakuan IPAT-BO lebih banyak dibanding perlakuan konvensional, sedangkan bobot kering gulma terberat terjadi pada metode IPAT-BO dengan jarak tanam $35 \mathrm{~cm} \times 35 \mathrm{~cm}$.

Kata kunci : IPAT-BO, Jarak Tanam, Komposisi Gulma
\end{abstract}

\begin{abstract}
The research was aimed to assess the effect of different plant spacing to weed composition and lowland rice yield in SOBARI and conventional irrigation methods. The experiment had been conducted in Farmers Groups Sadang Mukti, Sadang Sari Village, Bandung District, West Java at $668 \mathrm{~m}$ above sea level, from April 2013 to July 2013. It was arranged in split plot design, consisted of two factor, irrigation methods factor (M) as main plot, namely: irrigation methods in SOBARI $\left(m_{1}\right)$ and conventional $\left(m_{2}\right)$,subplot was plant spacing factor (J), which consisted of four levels of factors, namely: $30 \times 35 \mathrm{~cm}, 30 \times 25 \mathrm{~cm}, 35$ $\times 35 \mathrm{~cm}$, and $30 \times 30 \mathrm{~cm}$. The results showed that there was interaction between irrigation method and plant spacing on the value of domination number of weeds, and weed dry weight. Dominantweeds in SOBARI method were more than conventional treatment, weed dry weight in SOBARI method with spacing of $35 \mathrm{~cm} \times 35 \mathrm{~cm}$ had greater than the other treatments.
\end{abstract}

Keywords: SOBARI, Plant Spacing, Weed Composition 


\section{PENDAHULUAN}

Dari aspek pengelolaan air, usaha tani sawah secara konvensional pada umumnya dilakukan dengan penggenangan secara terus-menerus, hal ini merupakan salah satu upaya untuk mengendalikan gulma, di lain pihak kondisi sumber daya air semakin terbatas saat ini sehingga perlu dilakukan berbagai tindakan untuk mengatasinya, termasuk pengelolaan air dalam usahatani padi sawah, salah satu teknologi yang dapat diterapkan adalah pendekatan teknologi Intensifikasi Padi Aerob Terkendali-Berbasis Organik (IPAT-BO) yang merupakan sistem produksi padi holistik terpadu berbasis input lokal (kompos jerami, pupuk hayati, dan input lainnya) dengan konsep LEISA (Low External Input Sustainable Agriculture) dan manajemen tata air, tanaman dan pemupukan untuk memanfaatkan kekuatan biologis tanaman (potensi sistem perakaran dan jumlah anakan produktif) maupun kekuatan biologis tanah atau soil biological power (kelimpahan organisme tanah menguntungkan) berdasarkan rancang bangun teknologi dan manajemen input untuk mencapai target produksi (input oriented management) secara terencana (by design) (Simarmata, 2008).

IPAT-BO juga menerapkan jarak tanam yang lebar, karena semakin lebar jarak tanam, semakin luas daerah perakaran, dan berdasarkan kajian lapang jarak tanam minimal adalah $30 \mathrm{~cm} \times 30 \mathrm{~cm}$ dan maksimal $50 \mathrm{~cm} \times 50 \mathrm{~cm}$, di lain pihak jarak tanam dapat memainkan peran penting dalam meminimalkan tekanan gulma pada padi dalam kondisi tanah aerobik. Jarak tanam menunjukkan korelasi negatif dengan biomasa gulma namun hubungan positif dengan hasil padi, karena menurut Norhidayati Bt. Sunyob, et al. (2012) jarak tanam lebih sempit bisa diadopsi untuk mendapat hasil tanaman padi yang tinggi dan penekanan gulmayang lebih baik dalam program pengelolaan gulma terpadu untuk padi aerobik.

Pada IPAT-BO, kebutuhan air hanya setengah hingga sepertiga dari cara konvensional, lahan sawah dikondisikan lembab atau macak-macak tanpa digenangi. Hal ini menghemat penggunaan air sampai $30 \%$, namun demikian kondisi tersebut akan memacu pertumbuhan dan perkembangan gulma sehingga gulma yang tumbuh akan lebih banyak dibanding sawah yang digenangi (Simarmata dan Yuwariah, 2008). Ketinggian air yang digunakan pada teknologi IPAT-BO hanya mencapai ketinggian macak-macak. Dengan demikian tanaman padi dan aktivitas di daerah rhizosfer padi mendapat kesempatan untuk berada dalam kondisi aerob bergantian dengan kondisi anaerob. Hal tersebut akan memberi kesempatan akar untuk mendapatkan udara sehingga dapat berkembang lebih dalam, mencegah timbulnya keracunan besi, mencegah penimbunan asam organik dan gas $\mathrm{H}_{2} \mathrm{~S}$ yang menghambat perkembangan akar (Ihsan, 2011).

Hasil penelitian Bhagirath dan David (2011), baik pada musim kemarau ataupun musim hujan, jarak tanam yang lebih lebar $(30 \mathrm{~cm} \times 30 \mathrm{~cm}$ ) rentan terhadap persaingan gulma. Informasi yang diperoleh dari studi ini juga menunjukkan bahwa hasil panen padi aerobik yang lebih baik didapat pada jarak tanam $15 \mathrm{~cm} \times 15 \mathrm{~cm}$ dan 10-20-10 cm dibanding $30 \mathrm{~cm} \times 30 \mathrm{~cm}$, dan jika pengendalian gulma dilakukan setelah 8 minggu setelah tanam, maka manfaat sangat sedikit terhadap penurunan hasil tanaman padi. Padi yang ditanam dengan jarak tanam $30 \mathrm{~cm} \times 30 \mathrm{~cm}$ menghasilkan 
biomassa gulma yang lebih besar dan sedikit hasil gabah dibandingkan jarak tanam $15 \mathrm{~cm} \times 15 \mathrm{~cm}$ dan 10-20-10 cm. Produksi padi berkurang 94\%-96\% jika tanpa pengendalian gulma. Periode kritis pada musim hujan adalah 31 hari pada jarak tanam 10-20-10 cm, 34 hari pada jarak tanam $15 \mathrm{~cm}$ dan 43 hari pada jarak tanam $30 \mathrm{~cm}$, sedangkan pada musim kemarau, periode kritisnya 43 hari pada jarak tanam 10-20-10 cm, 39 hari pada $15 \mathrm{~cm}$ dan 49 hari pada $30 \mathrm{~cm}$.

Berdasarkan uraian di atas, maka perlu dilakukan penelitian untuk mengetahui pengaruh jarak tanam yang berbeda terhadap komposisi gulma pada metode pengairan secara IPAT-BO dan konvensional.

\section{BAHAN DAN METODE}

Bahan-bahan yang digunakan pada percobaan ini adalah benih padi varietas Sintanur yang ditanam pada petakan sawah. Pupuk dasar yang digunakan berupa pupuk kompos jerami, Urea, SP-36 dan $\mathrm{KCl}$. Untuk mencegah hama dan penyakit tanaman digunakan pestisida.

Pelaksanaan percobaan dilakukan di lahan sawah Gabungan Kelompok Tani Sadang mukti Kampung Sadang Sari RT 01/04 Kelurahan Andir Kecamatan Baleendah Kabupaten Bandung Jawa Barat yang terletak pada ketinggian $668 \mathrm{~m}$ di atas permukaan laut, jenis tanah Latosol, curah hujan rata-ratanya adalah 1911,9 mm per tahun, tipe iklim $D_{4}$ menurut Klasifikasi Oldeman (1975). Percobaan dilaksanakan pada bulan April 2013 sampai bulan Juli 2013.

Penelitian menggunakan metode eksperimen, dengan Rancangan Petak
Terpisah, 3 kali ulangan, sebagai petak utama adalah : faktor metode pengairan (M), yang terdiri dari pengairan secara IPATBO dan konvensional, sedangkan anak petak adalah jarak tanam (J), yang terdiri dari : $30 \times 35 \mathrm{~cm}, 30 \times 25 \mathrm{~cm}, 35 \times 35 \mathrm{~cm}$, dan $30 \times 30 \mathrm{~cm}$. Setiap petak luas lahannya adalah $4 \mathrm{~m} \times 5 \mathrm{~m}$, pada tiap petak percobaan ditentukan sampel untuk pengamatan gulma yang letaknya pada arah diagonalnya masing-masing untuk pengamatan destruktif dan sisanya untuk pengamatan hasil dan komponen hasil. Pengendalian gulmanya dilakukan secara manual menggunakan tangan pada saat umur tanaman 20 dan 50 hari setelah tanam (HST).

Bibit dipindahkan ke lahan setelah mencapai umur 10-15 hari setelah semai, dengan menggunakan sistem penanaman IPAT-TS (twin seedling), dengan cara ditanami sebanyak 2 bibit tanaman umur 10-15 HST dengan jarak $5 \mathrm{~cm}$ yang ditanam dangkal pada kedalaman sekitar 2-3 cm. Kondisi air pada saat tanam adalah "macakmacak" (tanah yang basah tetapi bukan tergenang).

Metode pengairan pada perlakuan IPATBO dilakukan dengan penggenangan macakmacak (tinggi air $0 \mathrm{~cm}$ ) pada awalnya, kemudian pasokan air dihentikan dan muka air dibiarkan turun secara alami. Pemberian air irigasi hingga tinggi air $0 \mathrm{~cm}$ dilakukan kembali manakala muka air tanah telah turun dan mencapai batas kedalaman $-5 \mathrm{~cm}$ di bawah permukaan tanah.

Aplikasi pupuk kompos jerami dilakukan satu minggu sebelum tanam dengan dosis 2,5 ton ha $^{-1}$. Untuk menambah kandungan nutrisi diberikan pula pupuk anorganik, yaitu urea sebanyak $250 \mathrm{~kg} \mathrm{ha}^{-1}, \mathrm{SP}-3650 \mathrm{~kg}$ $\mathrm{ha}^{-1}$, dan TSP $50 \mathrm{~kg} \mathrm{ha}^{-1}$. Aplikasi pupuk urea dilakukan sebanyak $3 \times$ yaitu pada saat 
tanam, 28 Hari Setelah Tanam (HST) dan 50 HST. Pupuk SP-36 dan KCl diaplikasikan sebanyak $1 \times$ yaitu pada saat tanam. Pengendalian hama dan penyakit dilakukan saat ada serangan dengan cara fisik, mekanik atau dengan pestisida tergantung serangan.

Variabel yang diamati pada penelitian ini adalah bobot kering gulma, dan nilai jumlah dominasi gulma. Pengamatan dilakukan terhadap 2 sampel setiap plot menggunakan metode kuadrat $(50 \mathrm{~cm}$ x 50 $\mathrm{cm}$ ) (Tjitrosudirdjo et al., 1998). Gulma yang didapat dicabut, lalu dibersihkan sampai ke akar-akarnya, lalu dimasukkan ke dalam amplop yang sudah diberi label untuk dilakukan identifikasi. Data yang didapat digunakan untuk menghitung nisbah jumlah dominasi gulma (NJD) yang ada.

\section{HASIL DAN PEMBAHASAN}

\section{Bobot Kering Gulma}

Hasil analisa terhadap bobot kering gulma dapat dilihat pada Tabel 1, 2, dan 3 yang menunjukkan bahwa terjadi interaksi antara metode pengairan dan jarak tanam terhadap bobot kering gulma.

Tabel 1. Pengaruh Interaksi antara Metode Irigasi dengan Jarak Tanam Terhadap Bobot Kering Gulma (g) pada Umur 30 HST

\begin{tabular}{ccccc}
\hline Perlakuan & \multicolumn{4}{c}{ Jarak Tanam } \\
\cline { 2 - 5 } Metode Irigasi & $\mathrm{j}_{1=30 \times 35 \mathrm{~cm}}$ & $\mathrm{j}_{2}=30 \times 25 \mathrm{~cm}$ & $\mathrm{j}_{3}=35 \times 35 \mathrm{~cm}$ & $\mathrm{j}_{4=30 \times 30 \mathrm{~cm}}$ \\
\hline \multirow{2}{*}{ IPAT-BO } & $4,61 \mathrm{a}$ & $1,44 \mathrm{a}$ & $2,64 \mathrm{a}$ & $1,92 \mathrm{a}$ \\
& $\mathrm{A}$ & $\mathrm{A}$ & $\mathrm{A}$ & $\mathrm{A}$ \\
Konvensional & $0,00 \mathrm{~b}$ & $1,05 \mathrm{a}$ & $0,00 \mathrm{~b}$ & $0,00 \mathrm{~b}$ \\
& $\mathrm{~A}$ & $\mathrm{~A}$ & $\mathrm{~A}$ & $\mathrm{~A}$
\end{tabular}

Keterangan : Angka rata-rata yang diikuti huruf yang sama arah vertikal (huruf kecil) dan arah horizontal (huruf kapital) tidak berbeda nyata menurut Uji Jarak Berganda Duncan pada taraf nyata 5\%.

Pada umur 30 hari setelah tanam (30 HST), bobot kering gulma yang terberat dicapai oleh perlakuan IPAT-BO (Tabel 1), hal ini terjadi karena salah satu pengendalian gulma secara kultur teknis pada padi sawah dapat dengan penggenangan. Kondisi tanah yang tergenang menciptakan suasana anaerob sehingga perkecambahan biji gulma dapat dihambat. Penggenangan juga menyebabkan penghambatan suplai oksigen pada proses respirasi di sekitar perakaran, sedangkan pada perlakuan IPAT-BO lahan sawahnya relatif tidak tergenang, sehingga penetrasi cahaya sinar matahari tinggi akibatnya merangsang perkecambahan bijibiji gulma yang dorman di dalam tanah.
Pada umur 60 dan 90 HST, bobot kering gulma yang terberat dicapai oleh perlakuan IPAT-BO dengan jarak tanam $35 \mathrm{~cm} \times 35 \mathrm{~cm}$ (Tabel 2 dan 3), hal ini terjadi karena pada perlakuan tersebut selain lahan sawahnya relatif tidak tergenang, jarak tanamnya juga relatif lebar, sehingga memungkinkan biji gulma yang dorman di dalam tanah berkecambah dan tumbuh, akibat adanya ruang tumbuh yang lebih lebar dan penetrasi cahaya matahari yang diperlukan untuk perkecambahan biji dapat bebas dimanfaatkan oleh biji-biji gulma yang berada di atas tanah. Hal ini sesuai dengan hasil penelitian Chauhan dan David (2011) yang menyatakan baik pada musim kemarau ataupun musim hujan, jarak tanam yang lebih lebar $(30 \mathrm{~cm} \times 30 \mathrm{~cm})$ rentan 
terhadap persaingan gulma, sehingga pada jarak tanam tersebut biomassa gulmanya lebih besar dibanding jarak tanam $15 \mathrm{~cm} \mathrm{x}$ $15 \mathrm{~cm}$ dan $10-20-10 \mathrm{~cm}$.

Tabel 2. Pengaruh Interaksi antara Metode Irigasi dengan Jarak Tanam terhadap Bobot Kering Gulma (g) pada Umur 60 HST

\begin{tabular}{ccccc}
\hline Perlakuan & \multicolumn{4}{c}{ Jarak Tanam } \\
\cline { 2 - 5 } Metode Irigasi & $\mathrm{j}_{1=30 \times 35 \mathrm{~cm}}$ & $\mathrm{j}_{2}=30 \times 25 \mathrm{~cm}$ & $\mathrm{j}_{3}=35 \times 35 \mathrm{~cm}$ & $\mathrm{j}_{4=30 \times 30 \mathrm{~cm}}$ \\
\hline \multirow{2}{*}{ IPAT-BO } & $5,30 \mathrm{a}$ & $2,70 \mathrm{a}$ & $8,83 \mathrm{a}$ & $0,40 \mathrm{a}$ \\
& $\mathrm{AB}$ & $\mathrm{BC}$ & $\mathrm{A}$ & $\mathrm{C}$ \\
Konvensional & $1,90 \mathrm{a}$ & $0,77 \mathrm{a}$ & $0,20 \mathrm{~b}$ & $9,77 \mathrm{~b}$ \\
& $\mathrm{~B}$ & $\mathrm{~B}$ & $\mathrm{~B}$ & $\mathrm{~A}$ \\
\hline
\end{tabular}

Keterangan : Angka rata-rata yang diikuti huruf yang sama arah vertikal (huruf kecil) dan arah horizontal (huruf kapital) tidak berbeda nyata menurut Uji Jarak Berganda Duncan pada taraf nyata $5 \%$

Tabel 3. Pengaruh Interaksi antara Metode Irigasi dengan Jarak Tanam Terhadap Bobot Gulma (g) pada Umur 90 HST

\begin{tabular}{ccccc}
\hline Perlakuan & \multicolumn{4}{c}{ Jarak Tanam } \\
\cline { 2 - 5 } Metode Irigasi & $\mathrm{j}_{1}=30 \times 35 \mathrm{~cm}$ & $\mathrm{j}_{2=30 \times 25 \mathrm{~cm}}$ & $\mathrm{j}_{3=35 \times 35 \mathrm{~cm}}$ & $\mathrm{j}_{4=30 \times 30 \mathrm{~cm}}$ \\
\hline \multirow{2}{*}{ IPAT-BO } & $4,69 \mathrm{~b}$ & $12,89 \mathrm{a}$ & $13,33 \mathrm{a}$ & $13,61 \mathrm{a}$ \\
& $\mathrm{B}$ & $\mathrm{A}$ & $\mathrm{A}$ & $\mathrm{A}$ \\
Konvensional & $14,67 \mathrm{a}$ & $8,43 \mathrm{a}$ & $0,00 \mathrm{~b}$ & $0,00 \mathrm{~b}$ \\
& $\mathrm{~A}$ & $\mathrm{BC}$ & $\mathrm{C}$ & $\mathrm{C}$ \\
\hline
\end{tabular}

Keterangan : Angka rata-rata yang diikuti huruf yang sama arah vertikal (huruf kecil) dan arah horizontal (huruf kapital) tidak berbeda nyata menurut Uji Jarak Berganda Duncan pada taraf nyata $5 \%$.

\section{Nilai Jumlah Dominasi (NJD)}

Hasil analisis terhadap Nilai Jumlah Dominasi (NJD) dari gulma pada umur 30 HST (Tabel 4), menunjukkan bahwa pada perlakuan IPAT-BO gulma yang dominan ada tujuh jenis, yaitu dua dari golongan teki (Fimbristylis miliacea dan Cyperus iria), empat dari golongan berdaun lebar (Ludwigia octovalvis, Alternanthera sessilis (L),Portulaca oleracea,dan Monochoria vaginalis), satu golongan gramineae (Echicocloa cruss-galli).

Tabel 4 juga menunjukkan bahwa pada keempat jenis jarak tanam yang berbeda pada perlakuan IPAT-BO nilai koefisien komunitasnya di atas $75 \%$, artinya tak banyak perbedaan keadaan vegetasinya pada keempat jarak tanam tersebut.

Pada perlakuan konvensional gulmanya hanya tumbuh pada jarak tanam $30 \mathrm{~cm} \times 25$ $\mathrm{cm}$, dimana gulma yang dominan ada tiga jenis, yaitu : dua dari golongan berdaun lebar (Portulaca oleracea,dan Ludwigia octovalvis), dan satu dari golongan teki(Fimbristylis miliacea).

Umur 60 HST (Tabel 5) pada perlakuan IPAT-BO gulma yang dominan turun menjadi menjadi lima jenis, yaitu : dua dari golongan teki (Fimbristylis miliacea dan Cyperus iria), tiga dari golongan berdaun lebar (Ludwigia octovalvis, Alternanthera sessilis (L) dan Portulaca oleracea), selain itu nilai koefisien komunitas pada keempat jarak tanam yang berbedanya juga lebih kecil dari $75 \%$, hal tersebut menunjukkan bahwa terdapat perbedaan keadaan vegetasi pada keempat jarak tanam yang dipakai.

Pada perlakuan konvensional gulma yang dominan naik menjadi empat jenis, 
yaitu dua dari golongan berdaun lebar (Alternanthera sessilis (L), dan Ludwigia octovalvis), dua dari golongan teki : (Fimbristylis miliacea, Cyperus iria), dengan nilai koefisien komunitasnya berbeda antar jarak tanam yang satu dan yang lainnya, dimana nilai koefisien komunitas gulma pada jarak tanam $30 \mathrm{~cm} \times 25 \mathrm{~cm}$ dan $30 \mathrm{~cm}$ x $30 \mathrm{~cm}$ tidak berbeda, yaitu 85,91\%, sedangkan perlakuan jarak tanam yang lain koefisien komunitasnya berbeda bahkanpada jarak tanam $35 \mathrm{~cm} \times 35 \mathrm{~cm}$ gulmanya tidak ada yang tumbuh.

Tabel 4. Nilai Jumlah Dominasi Gulma (NJD)B Dengan Perlakuan Metode Pengairan dan Jarak Tanam Yang berrbeda pada Umur 30 HST .

\begin{tabular}{|c|c|c|c|c|}
\hline \multirow{2}{*}{ Jenis Gulma } & \multicolumn{4}{|c|}{ Nilai Jumlah Dominasi (NJD) Pada Jarak Tanam } \\
\hline & $\mathrm{j}_{1}=30 \times 35 \mathrm{~cm}$ & $\mathrm{j}_{2}=30 \times 25 \mathrm{~cm}$ & $\mathrm{j}_{3}=35 \times 35 \mathrm{~cm}$ & $\mathrm{j}_{4}=30 \times 30 \mathrm{~cm}$ \\
\hline \multicolumn{5}{|l|}{ IPAT-BO } \\
\hline Echicocloa cruss-galli & 10,92 & 4,30 & 14,70 & - \\
\hline Cyperus iria & 13,33 & 9,43 & 7,05 & - \\
\hline Fimbristylis miliacea & 45,80 & 38,74 & 27,12 & 46,13 \\
\hline Monochoria vaginalis & - & - & - & 11,31 \\
\hline Ludwigia octovalvis & 29,94 & 33,81 & 37,65 & 25,30 \\
\hline Alternanthera sessilis (L) & - & 13,72 & - & - \\
\hline Portulaca oleracea & - & & 13,48 & 17,26 \\
\hline Koefisien Komunitas $j_{1}$ dan $j_{2}$ & & 82,41 & & \\
\hline Koefisien Komunitas $\mathrm{j}_{1}$ dan $\mathrm{j}_{3}$ & & & 75,03 & \\
\hline Koefisien Komunitas $\mathrm{j}_{1}$ dan $\mathrm{j}_{4}$ & & & & 84,58 \\
\hline \multicolumn{5}{|l|}{ KONVENSIONAL } \\
\hline Fimbristylis miliacea & - & 24,62 & - & - \\
\hline Ludwigia octovalvis & - & 26,18 & - & - \\
\hline Portulaca oleracea & - & 49,20 & - & - \\
\hline
\end{tabular}

Keterangan: - = Tidak ditemukan gulma jenis tersebut

Umur 90 HST gulma dominan pada perlakuan IPAT-BO ada tiga jenis, yaitu : satu dari golongan gramineae (Echicocloa cruss-galli), dua dari golongan berdaun lebar (Alternanthera sessilis (L), dan Ludwigia octovalvis), koefisien komunitas antar perlakuan jarak tanam yang berbeda menunjukkan nilai yang lebih kecil dari 75\%, artinya keadaan vegetasinya berbeda pada jarak tanam yang dicoba. Pada perlakuan konvensional gulma dominannya hanya ada satu jenis, yaitu dari golongan gramineae (Echicocloa cruss-galli)yang tumbuh pada jarak tanam $30 \mathrm{~cm} \times 25 \mathrm{~cm}$ dan $30 \mathrm{~cm} \times 30$ $\mathrm{cm}$. Hal tersebut di atas sesuai dengan pendapat Mabbayad dalam Moody (1992) yang menyatakan bahwa genangan air menurunkan bobot gulma dan jumlah spesies gulma yang tumbuh. Sedangkan jarak tanam dalam hal ini kurang mempengaruhi jumlah dominasi gulma, karena jarak tanam yang dipakai pada penelitian ini relatif lebar, sehingga tersedia ruang yang luas untuk tumbuh gulma dan tanaman padi yang ditanam.

Dominasi gulma disetiap plot percobaan akan mempengaruhi rekomendasi pengendalian yang diterapkan. Keadaan ini memiliki implikasi terhadap cara pengendalian yang berbeda. 
Tabel 5. Nilai Jumlah Dominasi Gulma (NJD)B dengan Perlakuan Metode Pengairan dan Jarak Tanam yang berbeda pada Umur 60 HST

\begin{tabular}{|c|c|c|c|c|}
\hline \multirow{2}{*}{ Jenis Gulma } & \multicolumn{4}{|c|}{ NILAI JUMLAH DOMINAN (NJD) } \\
\hline & $\mathrm{j}_{1}=30 \times 35 \mathrm{~cm}$ & $\mathrm{j}_{2}=30 \times 25 \mathrm{~cm}$ & $\mathrm{j}_{3}=35 \times 35 \mathrm{~cm}$ & $\mathrm{j}_{4}=30 \times 30 \mathrm{~cm}$ \\
\hline \multicolumn{5}{|l|}{ IPAT-BO } \\
\hline Cyperus iria & 61,84 & - & 34,31 & - \\
\hline Fimbristylis miliacea & 38,16 & 46,99 & - & 100,00 \\
\hline Ludwigia octovalvis & - & 20,94 & 36,73 & - \\
\hline Alternanthera sessilis (L) & - & 17,02 & 28,95 & - \\
\hline Portulaca oleracea & - & 15,06 & & - \\
\hline Koefisien Komunitas $j_{1}$ dan $j_{2}$ & & 46,99 & & \\
\hline Koefisien Komunitas $\mathrm{j}_{1}$ dan $\mathrm{j}_{3}$ & & & 34,31 & \\
\hline Koefisien Komunitas $\mathrm{j}_{1}$ dan $\mathrm{j}_{4}$ & & & & 38,16 \\
\hline \multicolumn{5}{|l|}{ KONVENSIONAL } \\
\hline Cyperus iria & - & - & - & 58,52 \\
\hline Fimbristylis miliacea & 48,53 & 34,44 & - & - \\
\hline Ludwigia octovalvis & - & - & - & 14,50 \\
\hline Alternanthera sessilis (L) & 51,47 & 65,56 & - & 26,98 \\
\hline Koefisien Komunitas $\mathrm{j}_{1}$ dan $\mathrm{j}_{2}$ & & 85,91 & & \\
\hline Koefisien Komunitas $\mathrm{j}_{1}$ dan $\mathrm{j}_{3}$ & & & 0 & \\
\hline Koefisien Komunitas $\mathrm{j}_{1}$ dan $\mathrm{j}_{4}$ & & & & 26,98 \\
\hline
\end{tabular}

Keterangan: $\quad$-= Tidak ditemukan jenis gulma tersebut

Tabel 6. Nilai Jumlah Dominasi Gulma (NJD)Bdengan Perlakuan Metode Pengairan dan Jarak Tanam yang berbeda pada Umur 90 HST

\begin{tabular}{lcccc}
\hline \multicolumn{1}{c}{ Jenis Gulma } & \multicolumn{4}{c}{ NILAI JUMLAH DOMINAN (NJD) } \\
\cline { 2 - 5 } & $\mathrm{j}_{1=30 \times 35 \mathrm{~cm}}$ & $\mathrm{j}_{2=30 \times 25 \mathrm{~cm}}$ & $\mathrm{j}_{3=35 \times 35 \mathrm{~cm}}$ & $\mathrm{j}_{4=30 \times 30 \mathrm{~cm}}$ \\
\hline IPAT-BO & 46,99 & 100,00 & 100,00 & 100,00 \\
$\begin{array}{l}\text { Echicocloa cruss-galli } \\
\text { Ludwigia octovalvis }\end{array}$ & 16,94 & - & - & - \\
$\begin{array}{l}\text { Alternanthera sessilis (L) } \\
\text { Koefisien Komunitas } \mathrm{j}_{1} \text { dan } \mathrm{j}_{2}\end{array}$ & 36,07 & - & - & - \\
$\begin{array}{l}\text { Koefisien Komunitas } \mathrm{j}_{1} \text { dan } \mathrm{j}_{3} \\
\text { Koefisien Komunitas } \mathrm{j}_{1} \text { dan } \mathrm{j}_{4}\end{array}$ & & 46,99 & & \\
KONVENSIONAL & & & 23,49 & 46,99 \\
$\begin{array}{l}\text { Echicocloa cruss-galli } \\
\text { Keterangan: } \quad-=\text { Tidak ditemukan gulma jenis tersebut }\end{array}$ & & & \\
\hline
\end{tabular}




\section{SIMPULAN}

Berdasarkan hasil penelitian, maka dapt disimpulkan :

1. Terjadi interaksi antara metode pengairan dan jarak tanam terhadap bobot kering gulma, dan nilai jumlah dominasi gulma.

2. Gulma yang dominan pada perlakuan metode pengairan secara IPAT-BO lebih banyak dibanding pada perlakuan konvensional.

3. Bobot kering gulma pada perlakuan metode pengairan secara IPAT-BO dengan jarak tanam $35 \mathrm{~cm} \times 35 \mathrm{~cm}$ lebih berat dibanding perlakuan lainnya.

\section{UCAPAN TERIMAKASIH}

Terimakasih penulis sampaikan kepada, Program Pasca Sarjana, Universitas Padjadjaran, Direktur Jenderal Pendidikan Tinggi. Penyuluh Pertanian dan Ketua Gapoktan Sadang Mukti Desa Andir Kecamatan Baleendah Kabupaten Bandung, untuk fasilitas yang diberikan dan didukung dalam kegiatan penelitian ini. Tulisan ini adalah bagian dari disertasi Merry Antralina dengan bimbingan penulis kedua dan ketiga.

\section{DAFTAR PUSTAKA}

Chauhan, B. S. dan David E.Johnson. 2011. Row Spacing and Weed Control Timing Affect Yield of Aerobic Rice. Field Crops Research. Volume 121, Issue 2, 18 March 2011, Pages 226-231, http : // www.sciencedirect.com/science/article/pi i/S0378429010003229, diakses 3 Desember 2012.
Ihsan, N. 2011. Cara Pengairan Berselang pada Tanaman Padi. Badan Litbang Pertanian.

http://www.litbang.deptan.go.id/berita/o ne/995/, diakses pada tanggal 9 Desember 2012.

Norhidayati Bt. Sunyob, Abdul Shukor Juraimi, Md. Moshiur Rahman, Md. Parvez Anwar, Azmi Man, dan Ahmad Selamat. 2012. Planting Geometry and Spacing Influence Weed Competitiveness of Aerobic Rice. Journal of Food, Agriculture \& Environment Vol.10 (2): 330-336. 2012. WFL Publisher Science and Technology. Meri-Rastilantie 3 B, FI-00980 Helsinki, Finland.www.world-food.net.

Simarmata, T. 2008. Teknologi Intensifikasi Padi Aerob Terkendali Berbasis Organik (IPAT-BO) untuk Melipat Gandakan Produksi Padi dan Mempercepat Pencapaian Kedaulatan Pangan di Indonesia. Pidato pengukuhan jabatan guru besar dalam Ilmu Biologi Tanah pada Fakultas Pertanian UNPAD. Bandung. . dan Yuwariah Y. 2008. Teknologi Intensifikasi Padi Aerob Terkendali Berbasis Organik (IPAT-BO) untuk Melipat Gandakan Produksi Padi dan Mempercepat Kedaulatan Pangan. Fakultas Pertanian Universitas Padjadjaran Bandung. http : // www. Pdffactorry.com.

Tjitrosudirdjo, S., I.H. Zutomo, dan J. Wiroatmodjo. 1998. Pengelolaan Gulma di Perkebunan. Gramedia. Jakarta. 